\title{
Relationships that determine the quantitative block of financing in the scientific-informational and educational-production environment
}

\author{
Elena Sivak ${ }^{1 *}$, Svetlana Volkova $^{1}$, Oksana Pankratyeva $^{1}$, and Alexey Shleenko ${ }^{2}$ \\ ${ }^{1}$ Kursk State Agricultural Academy, Karl Marx Street, 70, Kursk, 305021, Russia \\ ${ }^{2}$ South-West state University, 50 let Octyabrya Street, 94, Kursk, 305040, Russia
}

\begin{abstract}
The efficiency of sowing and harvesting processes in agriculture is one of the most important components of the success of an agricultural firm. Natural and climatic conditions typical for the majority of Russian agricultural territories impose restrictions on the timing and the fundamental possibility of sowing and harvesting. Therefore, the low efficiency of sowing and harvesting processes leads to a corresponding decrease in the volume of crop production. A number of works [1-4] consider various approaches to increasing the efficiency of sowing and harvesting, however, a systematic approach to the management of agricultural company processes requires the identification of the most significant reasons for the decrease in the efficiency and addresses as a priority their elimination (or reduction in the strength of their influence). The paper analyzes the reasons for the inefficiencies of sowing and harvesting processes and provides recommendations for reducing the impact of these reasons.
\end{abstract}

\section{Introduction}

The purpose of this work is the selection of indicators characterizing the processes occurring in the information-scientific-educational-production environment (SINOP) corresponding to the quantitative block. Indicators refer to ages from 25 to 64 years, i.e. the period of time corresponding to the 35-year life cycle of a person, and starting from 6 years it covers its 54-year cycle [1]. Therefore, the quantitative block of creating conditions for the adaptation of students in the scientific and industrial sphere is important and determines the prospects for not only qualitative transformations in society, but also process transformations, closely related to the innovation economy.

\section{Materials and methods}

From the set of statistical indicators for the quantitative block, we have selected 10 indicators related on the one hand to the share of expenditures: on education from GDP; for

\footnotetext{
*Corresponding author: elena.sivak.77@mail.ru
} 
general secondary education; for secondary vocational education (SVE); for higher education (HE) and for higher education and secondary vocational, determined as a percentage [2].

On the other hand, the average life expectancy of learning from 6 years and the proportion of persons: population who graduated from secondary school; with secondary specialized education, with higher education, as well as with higher education and secondary specialized from the entire population, determined as a percentage.

For comparability of quantities, they are not convenient themselves, but their relations and dimensionlessness. Therefore, for the first indicator, which is an informational indicator for any country:

$$
\left.L_{1}=\frac{\text { Funding for education gross domestic product, } \%}{\text { verage expected duration of education over } 6 \text { years }} ; \frac{\%}{\text { year }}\right]
$$

For the rest L2, L3, L4, L5 they took dimensionless ones:

$$
\begin{aligned}
& L_{2}=\frac{\text { Financing for general secondary education from all education costs, } \%}{\text { Share of people who graduated from secondary school from the total population, } \%} ; \\
& L_{3}=\frac{\text { Financing for secondary vocational education, } \%}{\text { Share of persons with secondary specialized education from the total population, } \%} ; \\
& L_{4}=\frac{\text { Financing for higher education from all costs of education, } \%}{\text { Share of persons with higher education from the total population, } \%} ; \\
& L_{5}=\frac{\text { Financing for HE and vocational education from all costs of education, } \%}{\text { The share of people with HE and vocational education from the total population, } \%} ;
\end{aligned}
$$

Graphical, statistical methods of data processing and correlation-regression analysis were applied to the indicators. And also compiled a quantitative block in the form of a diagram of interactions of the selected indicators [3-5].

\section{Results}

The selected indicators are subsequently referred to in the diagram of interactions (Fig.1) as : L1 is the share of consumption in gross domestic product to 1 year of training (Fig.2); L2 - the proportion of expense per student, graduated from high school (Fig.3); L3 - the share of expense per student in the system of secondary specialized education (Fig.4); L4 - the share of expense per student in the higher education system (Fig.5); L5 - share of the expense per student in the systems of vocational and higher education (Fig.6) (table. 1). 


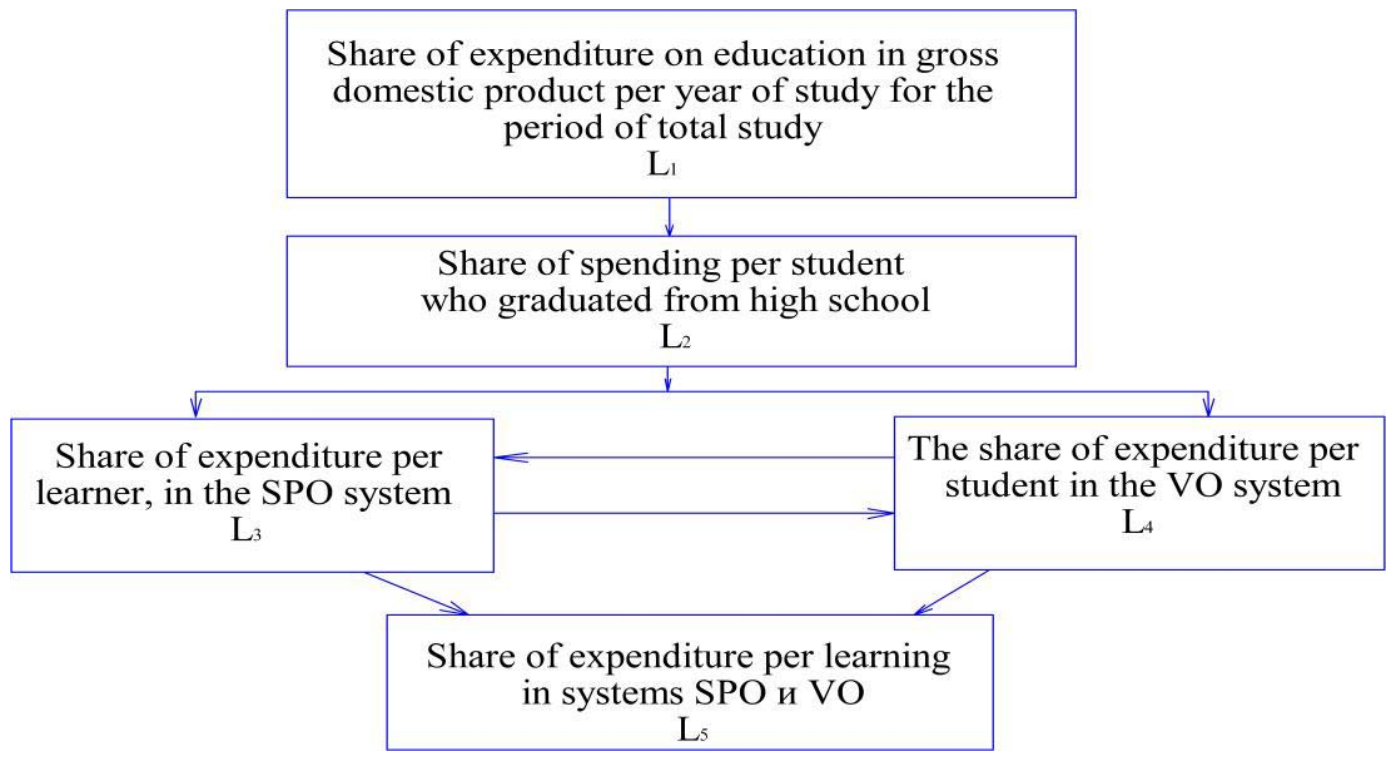

Fig. 1 Scheme of relationships on the organization of funding in different systems of education: secondary, secondary - special, higher.

Interval estimates of the L1 - L5 are presented in Table 1 in min - guaranteed minimum, max - possible maximum, made by formula:

$$
L^{-} t \rho \cdot S L * \sqrt{ } h-1<L<L \overline{+} t \rho \cdot S L * \sqrt{ } h-1
$$

$\mathrm{L}$ - is a measure of the quantitative block;

$\overline{\mathrm{L}}$ - The average sample of this indicator, determined by the formula (2);

n- sample size;

$t_{p}$-table value $t_{p}(P, n) t_{p}=(0,99 ; 11)=3,1$

$S_{L}^{*}$ - corrected root mean square deviation; according to the formula (3);

$$
\begin{gathered}
\bar{L}=\frac{\sum_{i=1}^{n} L_{i}}{n} \\
S_{L}^{*}=\sqrt{\frac{\sum_{i=1}^{n}\left(L_{i}-\bar{L}\right)}{n-1}}
\end{gathered}
$$


Table 1. SYNOP quantitative block indicators.

\begin{tabular}{|c|c|c|c|c|c|c|}
\hline $\mathbf{n} / \mathbf{n}$ & Year & $\mathbf{L}_{\mathbf{1}}$ & $\mathbf{L}_{\mathbf{2}}$ & $\mathbf{L}_{\mathbf{3}}$ & $\mathbf{L}_{\mathbf{4}}$ & $\mathbf{L}_{\mathbf{5}}$ \\
\hline 1 & 2008 & 0.316 & 0.495 & 0.891 & 0.685 & 0.726 \\
\hline 2 & 2009 & 0.312 & 0.500 & 0.796 & 0.731 & 0.745 \\
\hline 3 & 2010 & 0.312 & 0.465 & 1.153 & 0.686 & 0.781 \\
\hline 4 & 2011 & 0.280 & 0.461 & 0.805 & 0.619 & 0.651 \\
\hline 5 & 2012 & 0.279 & 0.491 & 0.134 & 0.606 & 0.344 \\
\hline 6 & 2013 & 0.293 & 0.486 & 0.197 & 0.531 & 0.361 \\
\hline 7 & 2014 & 0.287 & 0.491 & 0.296 & 0.375 & 0.349 \\
\hline 8 & 2015 & 0.269 & 0.460 & 0.830 & 0.367 & 0.442 \\
\hline 9 & 2016 & 0.25 & 0.503 & 0.528 & 0.290 & 0.332 \\
\hline 10 & 2017 & 0.249 & 0.428 & 0.406 & 0.264 & 0.294 \\
\hline 11 & 2018 & 0.255 & 0.421 & 0.635 & 0.241 & 0.299 \\
\hline$\Sigma$ & 22143 & 3.102 & 5.211 & 6.671 & 5.395 & 5.324 \\
\hline $\bar{L}$ & 2013 & 0.282 & 0.474 & 0.607 & 0.491 & 0.484 \\
\hline $\min$ & 2010 & 0.204 & 0.446 & 0.284 & 0.304 & 0.284 \\
\hline $\max$ & 2016 & 0.361 & 0.503 & 0.930 & 0.678 & 0.684 \\
\hline
\end{tabular}

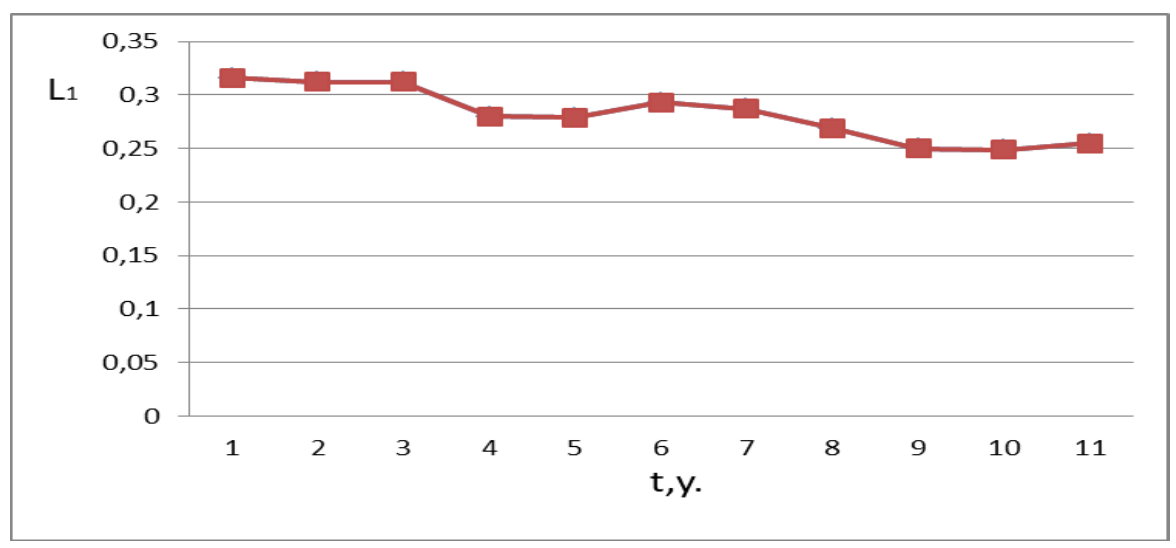

Fig. 2 The quantitative block is the share of expenditure in GDP for one year of study.

Dynamics of the presented indicator L1 with a tendency to decline by 2018[6].

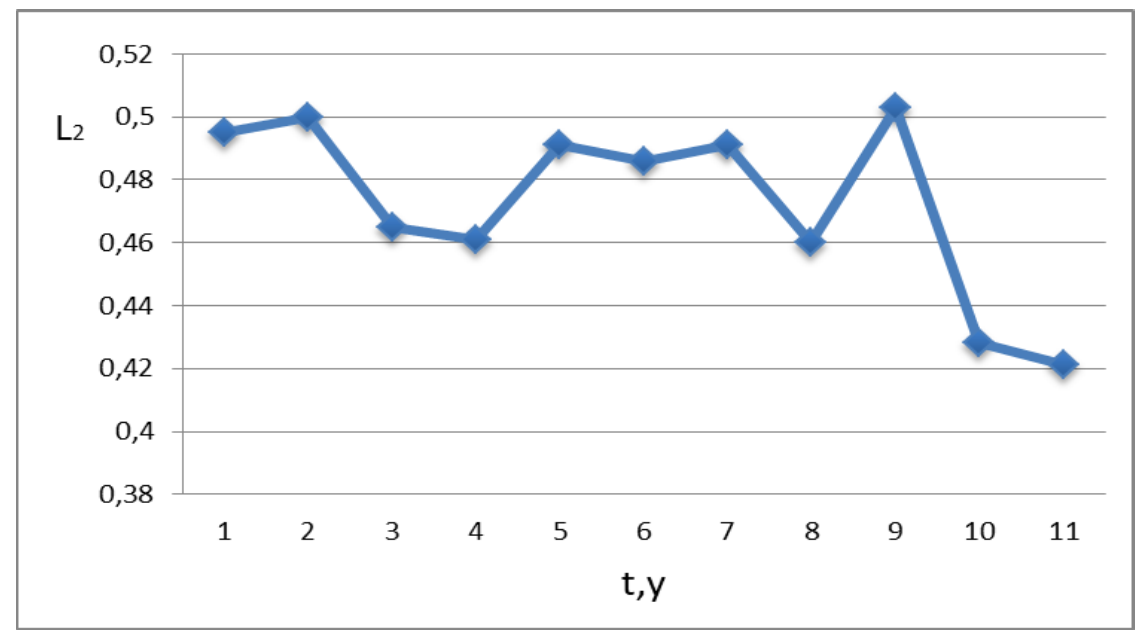

Fig. 3 The quantitative block of the share of expenditure per student who has completed secondary school. 
The analysis of the data on Figure 3 is similar to a swing with minimum values in 2011 and 2015 and a surge to a high in 2016 with a downward trend [7].

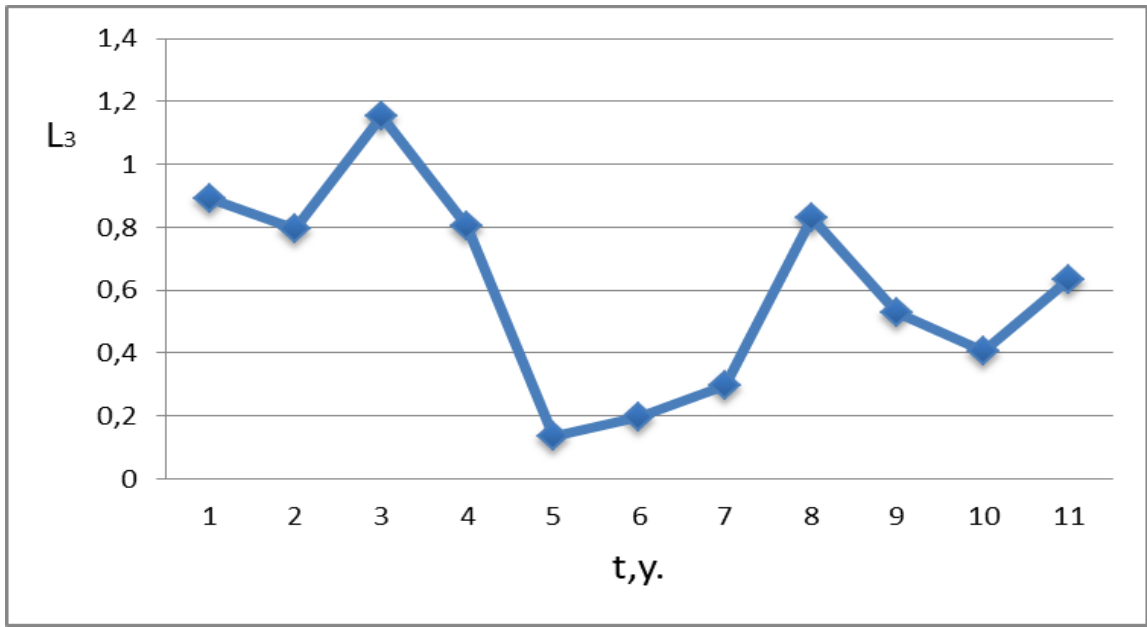

Fig. 4 The quantitative block of the share of the expenditure of one student in the SYSTEM.

The unevenness of funding is clearly presented by patterns in Figure 4 with a minimum value in 2012 with an upward trend by 2015 and generally from the current decline by 2018 .

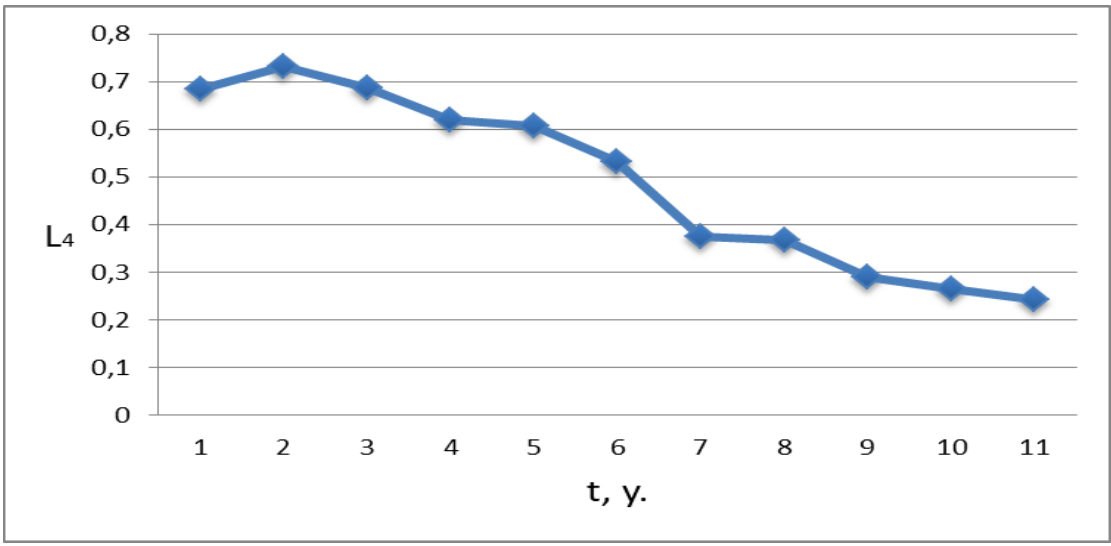

Fig. 5 Indicator of the quantitative block of the share of expenditure per student in the higher education system.

Funding for higher education has been steadily decreasing since 2009 . 


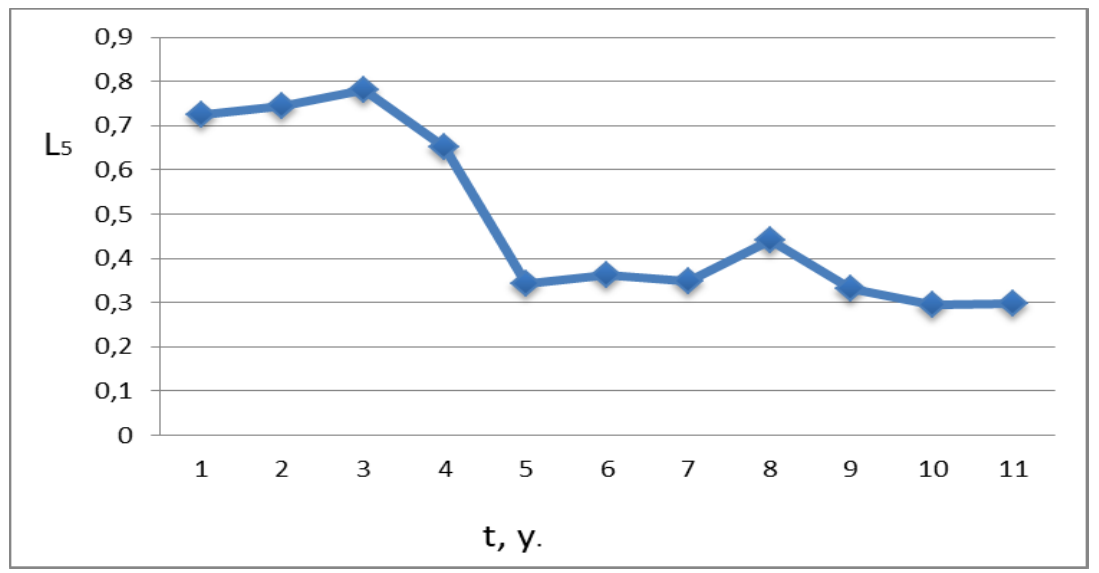

Fig. 6 Indicator of the quantitative block of the share of expenditures per student in the systems of secondary special and higher education.

The abrupt change in dynamics from 2010 to 2012 shows a decreasing trend by 2018 .

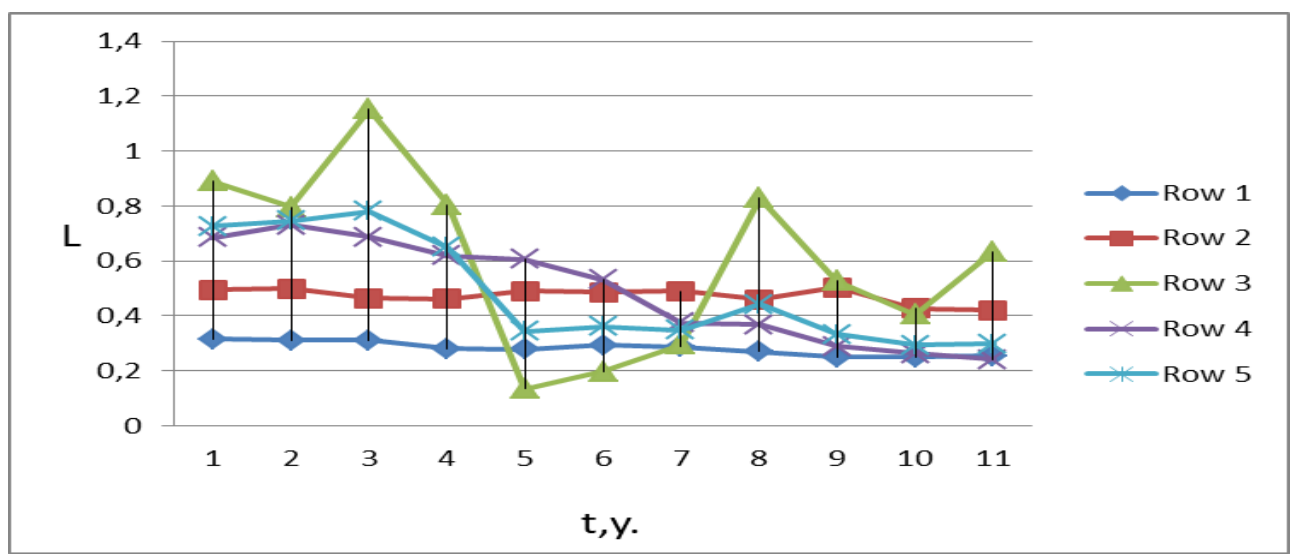

Fig. 7 Indicators of the quantitative block. BLUE: Row 1 - L1, Row 2 - L2, Row 3 - L3, Row 4 - L4, Row 5 - L5

SINOP is an information-scientific-educational-industrial environment.

For clarity of the dynamics of the processes described by the selected indicators, we will construct a distribution polygon, marking on the horizontal axis the time expressed in years $1-2008,2-2009, \ldots .11-2018$. Let's mark the indicators of the quantitative block vertically. L1 - L5 (fig. 7) [8].

4. Discussion. From the distribution polygons, it can be seen that there is a relationship between: $\mathrm{L} 2=\mathrm{f}(\mathrm{L} 1) ; \mathrm{L} 5=\mathrm{f}(\mathrm{L} 3)$ and $\mathrm{L} 4=\mathrm{f}(\mathrm{G})$

Table 2. Coefficients of correlation $\mathrm{rL}_{\mathrm{i}} \mathrm{L}_{\mathrm{j}}$-and direct regression between $\mathrm{L} 1$ and $\mathrm{L} 2$, $\mathrm{L} 3$ and $\mathrm{L} 5, \mathrm{~L} 4$ and $\mathrm{G}(\mathrm{i}=1,3 ; \mathrm{j}=2,4,5)$

\begin{tabular}{|l|l|l|l|l|l|}
\hline $\mathbf{n} / \mathbf{n}$ & $\mathbf{L}_{\mathbf{i}} \mathbf{L}_{\mathbf{j}}$ & $\mathbf{r}_{\mathbf{L i} \mathbf{L j}}$ & $\mathbf{b} \mathbf{L}_{\mathbf{j}} / \mathbf{L}_{\mathbf{i}}$ & $\begin{array}{l}\text { The closeness of the } \\
\text { connection }\end{array}$ & The regression line \\
\hline 1 & $\mathrm{~L}_{1} \mathrm{~L}_{2}$ & 0.52 & 0.59 & average closeness & $\mathrm{L}_{2}=0.59 \cdot \mathrm{L}_{1}+0.31$ \\
\hline 2 & $\mathrm{~L}_{3} \mathrm{~L}_{5}$ & 0.79 & 0.49 & very close & $\mathrm{L}_{5}=0.49 \cdot \mathrm{L}_{3}+0.19$ \\
\hline 3 & $\mathrm{G} \mathrm{L}_{4}$ & -0.97 & -0.055 & functional & $\mathrm{L}_{4}=-0.055 \cdot \mathrm{G}+0.821$ \\
\hline
\end{tabular}

From the analysis of correlation-regressive dependence we see that with the increase in GDP per year of study during the entire period of study increases by 0.59 units of funding 
per general secondary education per secondary school student, which shows direct regression with an increase per unit L1, L2 increases by 0.59 units [9-12].

From line number 2 in table. 2 we see that with an increase in L3 by 1 unit, L5 increases by 0.49 , since with an increase in funding for SPE, the total share of expenses for HE and SPE per student increases by 0.49 units.

From the third line of table 2 we see that annually the cost of HE decreases by 0.055 per student with $\mathrm{HE}$ and at this rate of attrition by 2033 , they can go to zero.

$-0.055 \mathrm{G}-0.821 \mathrm{q} 0$;

$\mathrm{G}$ q14.93 $\approx 150,8210,055$

In 15 years, and this will be 2033, the Higher School will have to switch to selfsufficiency, otherwise it will collapse, at least the traditional part of education of the Russian Federation.

From the found dependences for the further analysis it is possible to leave not five, but three indicators of L2, L5, L4 or L1, L3, L4 or depending on the interests of the researcher.

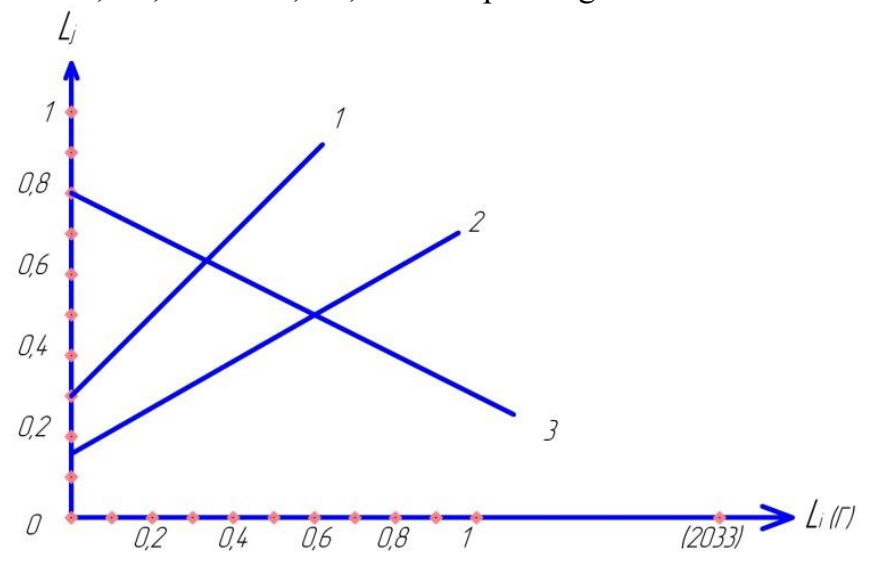

Fig. 8 Direct regressions. 1 -L2, 2- L5, 3 - L4.

From the graphical analysis of the distribution polygons in Fig. 7, we see that the costs of HE per student have been decreasing since 2010 (row 4) and are becoming even less than funding for general secondary education since 2014, and since 2017 it is less than the share of expenses from GDP per year of study during the entire period of study (row 1). Funding for open source software by 2018 becomes a priority (row 3) [13-15].

In the combined Fig. 8 of direct regressions, the tendency of a rapid fall in financing per capita for HE is decreasing (row 3) in comparison with other types of education (row 1.2).

Conclusions. Summarizing the analysis of the indicators of the quantitative block, we come to the following conclusions:

1. The five indicators selected, which can be narrowed down to three, reliably characterize the processes presented by SINOP .

2. The regularities found in the work make it possible to predict the processes characterizing the qualitative indicators associated with the employment of the population in the national economy.

3. In 2012, a sharp jump in the L3 indicator associated with the financing of open source software, the uneven development of the financing process in the form of a swing leads to qualitative changes in the same years in indicators related to the innovative activity of enterprises in the direction of their decrease.

4. A stepwise change in the direction of decreasing the fourth quantitative indicator associated with $\mathrm{HE}$ financing per student also negatively affected the quality indicators, not 
only a technological breakthrough did not happen, but the country generally stalled in development.

5. In the future, the indicators of the qualitative block related to the employment of graduates and the use of the process block in research and development of entrepreneurs with higher education and vocational education should be distinguished in a similar way . The totality of block interactions should be represented by an integrated circuit of the SINOP processes.

\section{References}

1. Y. Zhou, B.E. Journal of Economic Analysis \& Policy, 15, 997-1029 (2015) doi: 10.1515/bejeap-2014-0062

2. H. Mueller, B.E. Journal of Economic Analysis \& Policy, 15, 961-996(2015) doi: 10.1515/bejeap-2013-0084

3. P. Dubois, T.Vukina, B.E. Journal of Economic Analysis , 16, 1239-1272( 2016) doi: 10.1515/bejeap-2016-0026

4. J. Pi, Y. Ge, J.Yin, The B.E. Journal of Economic Analysis \& Policy, 17, 2015-2025 (2017) doi: 10.1515/bejeap-2015-0225

5. F. Akhtar, Accounting and Finance, 57, 3-43 (2017) doi: 10.1111/acfi.12149

6. N. Panigirtzoglou, European Financial Management, 10, 321-338 (2004) doi: $10.1111 / \mathrm{j} .1354-7798.2004 .00252 . \mathrm{x}$

7. M. Drenovak, B. Urošević, R. Jelic, European Financial Management, 20, 958-994 (2014) doi: 10.1111/j.1468-036X.2012.00649.x

8. I. Mathur, M. Singh, K.C. Gleason, European Financial Management, 10, 439-464 (2004) doi: 10.1111/j.1354-7798.2004.00258.x

9. T. Jandik, C.G. Rennie, European Financial Management, 14, 747-791(2008) doi: 10.1111/j.1468-036X.2007.00407.x

10. P. Chelley-Steeley, N. Lambertides, C.S. Savva European Financial Management, 25, 116-159 (2019) doi: 10.1111/eufm.12146

11. R. Fan, V. Tran, O. Talavera, European Financial Management, 26, 753-777 ( 2020 ) doi: 10.1111/eufm. 12245

12. A. Habib, M.D. Costa, H.J. Huang, M.B.U. Bhuiyan, L. Sun, Accounting and Finance, 60, 1023-1075 (2020) doi: 10.1111/acfi.12400

13. J. Que, X. Zhang Accounting and Finance, 60, 1077-1110 (2020) doi: 10.1111/acfi.12401

14. T. Marty, B. Vanstone, T. Hahn Accounting and Finance, 60, 1385-1434 (2020) doi: 10.1111/acfi.12466

15. G. Whittred, Accounting and Finance, 44, 121-122 (2004) doi: 10.1111/j.1467629X.2004.00110.x 